\title{
City Police Officer Dies After His Vehicle is Struck by a Civilian Motorist in a Federal Highway Intersection
}

\section{CASE SUMMARY}

On Wednesday morning, March 11, 2015, a city police officer was driving southbound on a federal highway to a neighboring city for training. The driving conditions were not ideal, as visibility was low due to heavy fog in the area and the roadway was wet. As the officer approached an intersection, a motorist, who was at the intersection attempting a left turn, struck the officer's cruiser on the right side causing him to lose control and spin into the northbound lane, where another vehicle collided with the police cruiser's passenger side.

Emergency Medical Services were notified of the incident at 7:18 am and arrived at 7:22 am. Three people were taken to a local hospital while the victim was transported to a major trauma center, where he succumbed to his injuries at 8:21 am.

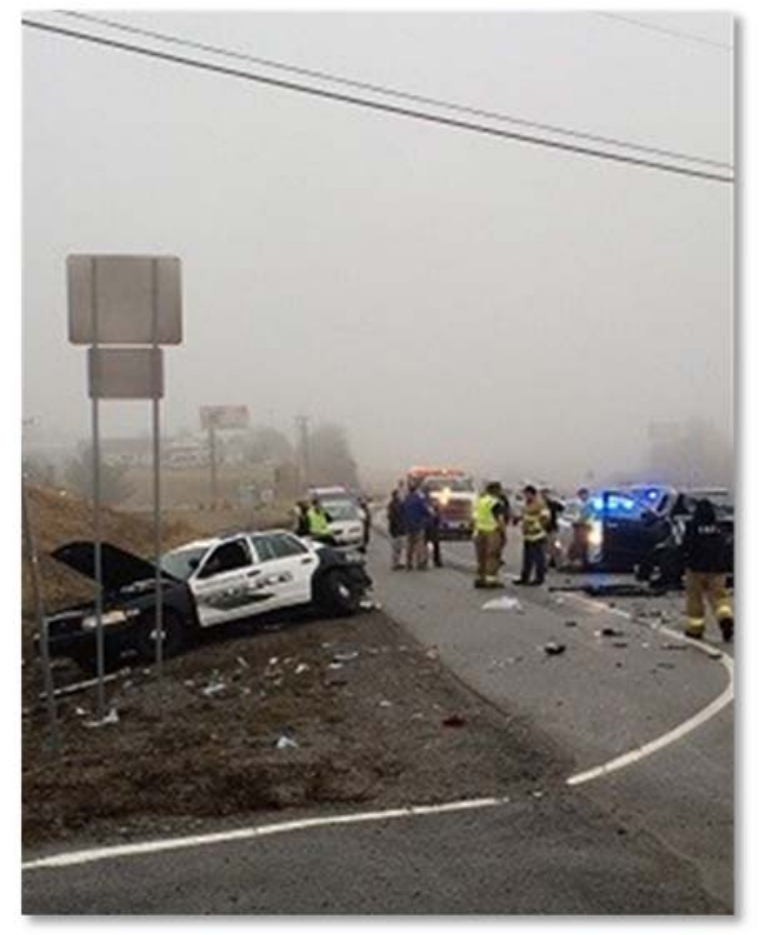

Figure 1. The final resting place of the police cruiser following the crash.

\section{Recommendations for prevention:}

- Law enforcement offices should implement safe driving policies.

- Law enforcement offices should implement an annual training for inclement driving. ${ }^{1-4}$ 


\section{EMPLOYER}

The employer was a city police department with 53 employees.

\section{SAFETY AND TRAINING PROGRAMS}

The employer had written safety programs and provided extensive training to employees.

Employees attend two weeks of training for hands-on defensive and pursuit driving techniques.

\section{VICTIM}

The victim was a 35-year-old college graduate and a U.S. Army veteran who had served with the police department for seven years. He had a wife and two sons.

\section{INCIDENT SCENE}
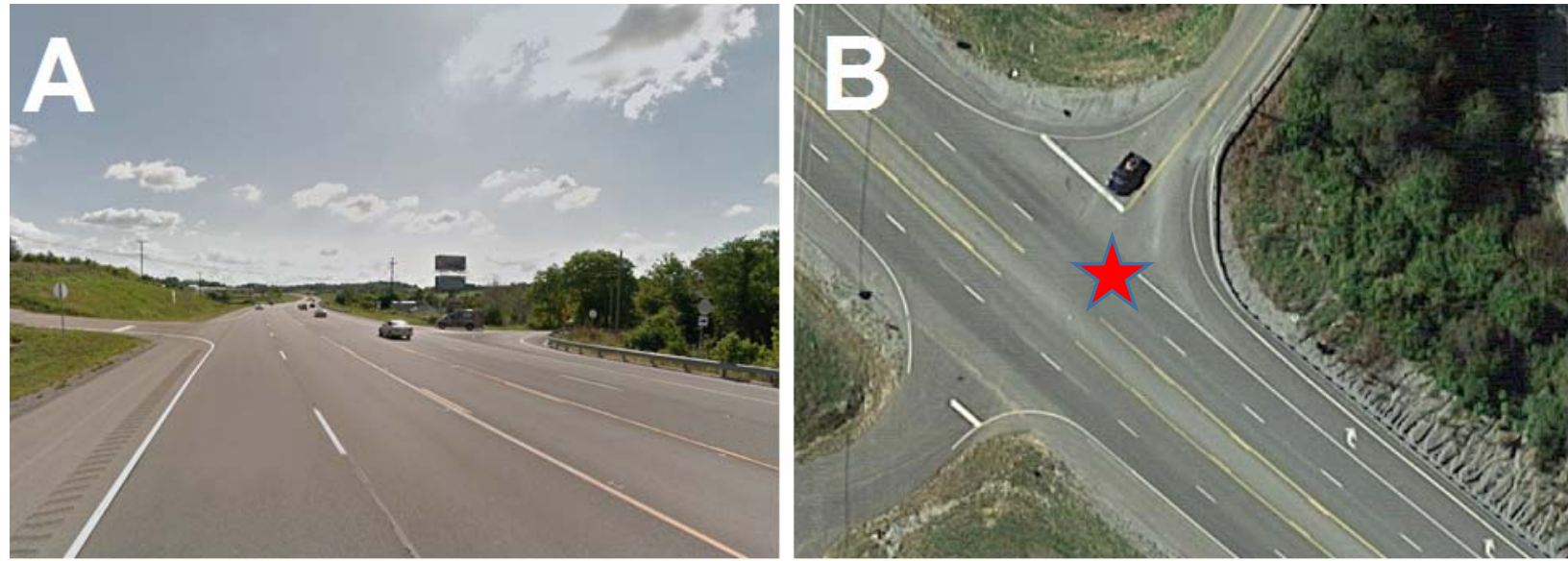

Figure 2. Street view and bird's-eye view of where the incident occurred. The star denotes the location of the initial impact (B).

The incident scene was a portion of a dark non-lit federal highway that was straight and level. The roadway featured two lanes in each direction, separated by a two-way left turn lane. Dense fog and wet roadway conditions were present at the time of the crash. There was no traffic light present at the intersection in which the incident took place.

\section{EQUIPMENT}

The vehicle was a black and white 2008 Ford Crown Victoria Police Interceptor.

\section{WEATHER}

At the time of the incident, the temperature was $50^{\circ} \mathrm{F}$ with $100 \%$ humidity, which was visible in the form of dense fog. Wind was blowing at approximately $3.5 \mathrm{mph}$ in the north-northwest 
direction. The dense fog present at the time of the crash was considered to be a contributing factor in this case.

\section{INVESTIGATION}

The Kentucky Fatality Assessment and Control Evaluation Program was notified through the media of a fatality involving a police officer due to a motor vehicle collision. An investigation was conducted.

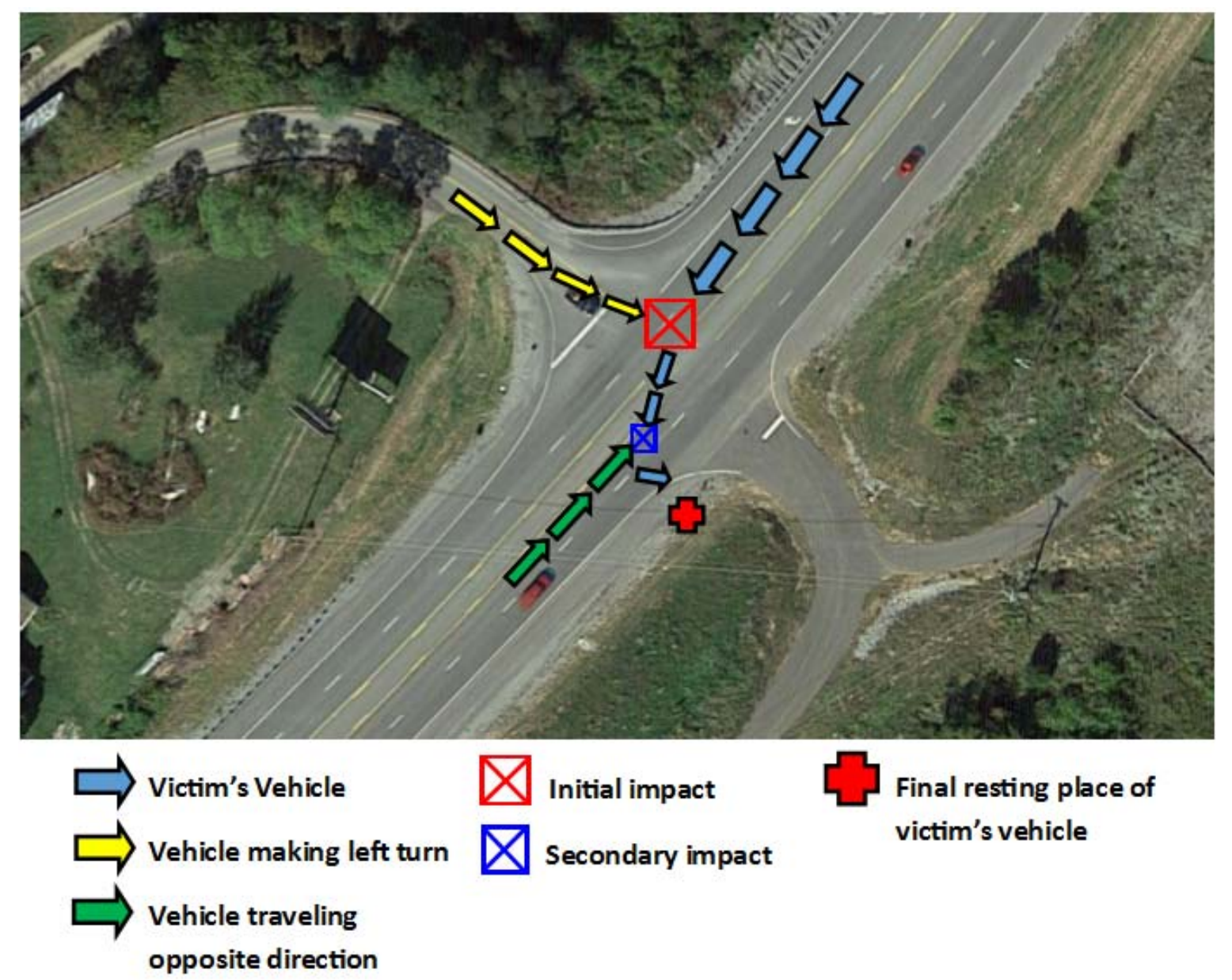

Figure 3. Bird's-eye view showing the trajectory of the victim's unit, the vehicle that was making a left turn, and the oncoming vehicle.

On Wednesday, March 11, 2015, the victim was driving a police cruiser to a neighboring city for training, traveling southbound on a federal highway. The visibility was low due to heavy fog in the area and the roadway was wet. As the officer approached an intersection (see figure 3), a 2012 Chevrolet Cruse was stopped and attempting a left turn to travel north. The Chevrolet pulled out and struck the police cruiser's right side causing the officer to lose control and spin into the northbound lane where he collided with a northbound 2010 Cadillac SRX. The victim's police cruiser came to rest on the northbound shoulder, facing east, 10 feet from the highway 
(see figure 4A). The Cadillac SRX stopped, facing north in the right northbound lane of the highway.
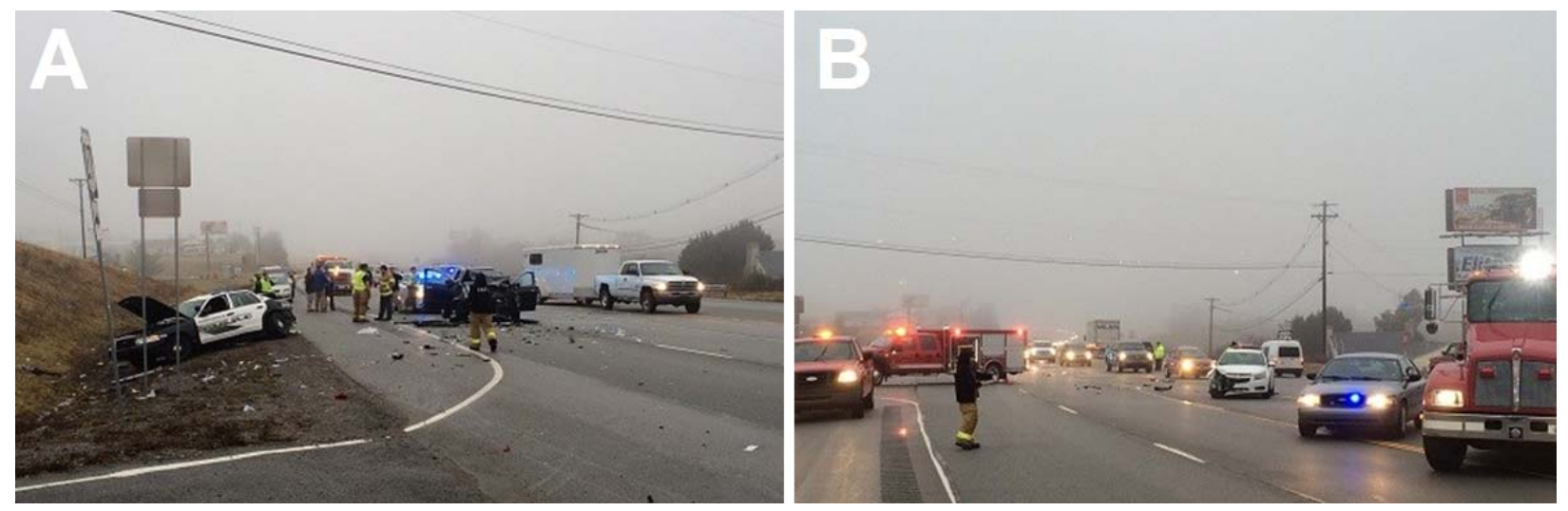

Figure 4. The final resting place of the police cruiser (A). Emergency personnel at the scene (B).

Emergency Medical Services were notified of the incident at 7:18 am and arrived at 7:22 am (see figure 4B). Three people were taken to a local hospital while the victim was transported to a major trauma center where he succumbed to his injuries at 8:21 am.

\section{CAUSE OF DEATH}

The cause of death was multiple blunt force trauma caused from a motor vehicle collision.

\section{CONTRIBUTING FACTORS}

Occupational injuries and fatalities are often the result of one or more contributing factors that ultimately result in injury or death. The investigation identified the following factors that may have contributed to the fatality:

- Limited visibility due to dense fog

- Wet road conditions

\section{RECOMMENDATIONS AND DISCUSSIONS}

Recommendation No. 1: Law Enforcement offices should implement safe driving policies.

Implementation of safe driving policies could bring awareness of the hazards officers face on a daily basis. Special emphasis should be placed on policies concerning driving in inclement weather conditions.

Recommendation No. 2: Law enforcement offices should implement an annual training for inclement driving. 
An annual training campaign to bring awareness of the impact fog has on driving should include:

- Reduced Speed.

- Increase the following distance between your car and the car ahead.

- Turn on low beam headlights, and/or fog lights to remain visible to other cars.

- Do not use high beam lights; they reflect the fog.

- Use windshield wipers and defrost control to prevent condensation.

- The safety practice of rolling down a window when approaching an intersection to listen for traffic before pulling into the intersection.

Studies have shown that most fog related accidents occur during the fall and winter months. Annual training prior to and during these seasons would likely help to reduce the number of fog related motor vehicle injuries and fatalities.

\section{KEYWORDS}

First Responders

Fog

Police

Motor Vehicle Collision

\section{REFERENCES}

${ }^{1}$ Driving in the Fog. Motorist News \& Driving Guideline

[http://www.smartmotorist.com/driving-guideline/driving-in-fog.html]

${ }^{2}$ How to Drive in Dense Fog. My Ford Owner Magazine [https://www.myfordmag.com/service/driving-in-fog]

${ }^{3}$ Safe Driving Tips. Kentucky office of Highway Safety [https://transportation.ky.gov/Highway-Safety/documents/SafeTips.pdf]

${ }^{4} H i d d e n$ highways: Fog and Traffic Crashes on America's Roadways. AAA Foundation for Traffic Safety

[https://www.aaafoundation.org/hidden-highways-fog-and-traffic-crashesamerica\%E2\%80\%99s-roads]

\section{PHOTO CREDIT}

Photo credits WKYT news and Google Maps.

\section{ACKNOWLEDGEMENTS}


The Kentucky FACE program would like to thank the State Highway Patrol, the coroner's office and Jamie Glen Whitaker for their assistance with this report.

\section{PROGRAM FUNDING}

The Kentucky Fatality Assessment \& Control Evaluation Program (FACE) is funded by grant 2U60OH008483-11 from the Centers for Disease Control and Prevention and the National Institute for Occupational Safety and Health.

Please take the time to complete our brief survey regarding this report:

(https://uky.az1.qualtrics.com/jfe/form/SV_0MQKU0pwMA3QjJz)

Electronic access to this full report can be found here:

(http://www.mc.uky.edu/kiprc/programs/face/files/15KY009.pdf)

\section{FACE on Social Media:}

https://www.facebook.com/Kentucky-FACE-Program$\underline{134135740092906 / \text { ?view_public for }=134135740092906}$

\section{http://www.twitter.com/KYFACEProgram}

This case report was developed by the Kentucky Fatality Assessment and Control Evaluation (FACE) Program. Kentucky FACE is a NIOSH-funded occupational fatality surveillance program with a goal of preventing fatal work injuries by studying the worker, the work environment, and the role of management, engineering, and behavioral changes in preventing future injuries. The FACE Program is located within the Kentucky Injury Prevention and Research Center (KIPRC), part of the University of Kentucky's College of Public Health.

Email: kyfaceprogram@uky.edu | Telephone: 859-257-5839 333 Waller Avenue Suite 242, Lexington, KY 40504 